\title{
LOS COMICIOS AUTONÓMICOS CATALANES DE 1999, UN CASO CURIOSO EN EL SISTEMA ELECTORAL PROPORCIONAL: VOTOS VERSUS ESCAÑOS
}

ÓSCAR IGNACIO MATEOS Y DE CABO 


\section{SUMARIO}

1. La campaña electoral en Cataluña. 2. La búsoueda del centro político. 3. Los pronósticos electorales. 4. Votos versus escaños. 5. Participación. 6. Los resultados electorales. 7. Pactos post-electorales. 8. Análisis de los reSULTADOS ELECTORALES. 


\title{
LOS COMICIOS AUTONÓMICOS CATALANES DE 1999, UN CASO CURIOSO EN EL SISTEMA ELECTORAL PROPORCIONAL: VOTOS VERSUS ESCAÑOS
}

\author{
POR \\ ÓSCAR IGNACIO MATEOS Y DE CABO \\ Profesor de Derecho Constitucional de la Universidad \\ Rey Juan Carlos de Madrid
}

\section{LA CAMPAÑA ELECTORAL EN CATALUÑA}

La campaña electoral de los comicios autonómicos catalanes se inició en la medianoche del viernes 1 de octubre de 1999, para prolongarse en los quince días siguientes de campaña oficial, con un disputado pulso entre los dos candidatos con mayores posibilidades para formar gobierno en Cataluña: Jordi Pujol por Convergència $i$ Unió (CiU), que pese a su edad de 69 años y los rumores en torno a su sucesión, declara no estar ni "agotado ni exhausto"; y el ex alcalde de Barcelona Pasqual Maragall por el Partido Socialista de Cataluña (PSC), que junto con Iniciativa per Catalunya-Verds (IC-V), se habia propuesto poner fin a los 19 años ininterrumpidos de gobiernos de CiU. En realidad, la larga precampaña de los socialistas comenzó hace más de un año, cuando Maragall creó una coalición con independientes, denominada Ciutadans pel Canvi, con el objeto de acortar la ventaja que CiU obtuvo en las elecciones autonómicas de 1995. 
El logro de una mayoría cómoda que permitiese la gobernabilidad de Cataluña fue esgrimido por las dos principales coaliciones electorales, como uno de los grandes ejes de la campaña en Cataluña. Jordi Pujol se había fijado como meta la consecución de 62 diputados -dos más que en los anteriores comicios- consiguiendo finalmente 56 escaños. Su competidor más inmediato, Pasqual Maragall, orienta su coalición de tres partidos, con el claro deseo de representar una alternativa de gobierno frente a la larga permanencia de los gobiernos de CiU.

Por otro lado, los mensajes políticos de los líderes de los distintos partidos a lo largo de la campaña, no son, en general, excesivamente cautivadores para el electorado', por lo que algunos comentaristas políticos en vista de las propuestas, pusieron de relieve que el interés electoral de algunos de estos partidos había sustituido al debate de ideas ${ }^{2}$.

En cuanto a las tácticas electorales, los dos candidatos con mayores posibilidades de ganar las elecciones, evitaron durante la campaña entrar en cuestiones polémicas, como la ley del catalán, y enviaron a sus lugartenientes Josep Duran Lleida (UDC) y Joaquín Nadal (PSC), entre otros, a terciar en estas polémicas para intentar "fajarse" en terrenos peligrosos ${ }^{3}$. No obstante, a pesar de ese intento por no convertir el diseño lingüístico en Cataluña en controversia política durante la campaña electoral, el otro gran eje electoral de los comicios catalanes gira precisamente en torno a la política lingüística, cuestión que divide a los partidos contendientes en posiciones tan dispares como la defensa de la técnica de la inmersión lingüística, importada del Quebec por los convergentes, los elementos atenuantes de dicha inmersión que propugna Maragall, el bilingüismo castellano-catalán de los populares, hasta el trilingüismo de Esquerra Republicana, que defiende la preeminencia del catalán, complementado por el castellano y el inglés ${ }^{4}$.

1 En los mensajes electorales de los principales líderes políticos que concurren a estos comicios, Jordi PuJol CiU), promete más poder político y económico para Cataluña. Pasqual MARAGaLL (PSC), centra su atención en mostrarse como la alternativa y el cambio frente al gobierno de CiU. Alberto Fernández (PP), gira su discurso en torno a "frenar los excesos nacionalistas" desde la centralidad social. CAROD-RoviRA (ERC), se ofrece como garante de una política nacionalista. Rafael RiBó (IC-V), representa el apoyo que necesita Maragall para poder gobernar. Vid. ABC (1-10-1999.

2 Por ejemplo Carlos Herrera en ABC (1-10-1999), no dudó en calificarla de "campaña sin café, sin chispa, sin mérito".

3 El Pais (2-10-1999).

4 Puig. V. "Del monolingüismo al trilingüismo», en $A B C$ (4-10-1999). El deseo de rebajar la polémica en torno a la política lingüística hace que los dos 
Por último, la otra gran cuestión junto con la economía -que trataremos aparte en el epígrafe siguiente-, viene representada por la forma de Estado propuesta ${ }^{5}$, sobre la que encontramos una gran variedad de ideas que van desde la soberanía compartida de igual a igual entre España y Cataluña de CiU, el federalismo asimétrico de Maragall ${ }^{6}$, la defensa del Estatuto del PP, y la idea de nación, con una clara tendencia al independentismo de ERC ${ }^{7}$.

\section{LA BÚSQUEDA DEL CENTRO POLÍTICO}

Si aceptamos una posible relación entre la situación económica y las grandes líneas de la ideología política, tal y como afirmaban ciertos políticos de corte clásico, la sociedad catalana se encuentra situada en la representación de ingresos medios por habitante -en un $90 \%-$, precisamente en la zona media de nuestro primer gráfico [ver gráfico $\mathrm{n}^{\circ}$ 1]. Por lo que si nos referimos a los ingresos, la podriamos situar dentro de la clase media.

Del análisis del gráfico utilizado -que compara la renta familiar disponible por habitante entre Cataluña y el conjunto de España-, es claramente apreciable que en Cataluña destaca la ausencia de personas con ingresos por debajo del nivel 4 , mientras en el conjunto español la mitad de la población se engloba dentro de los cinco menores ingresos de la tabla, cuando en Cataluña no llega al $1 \%$.

principales candidatos, Jordi Pujol y Pasqual Maragall, traten de "pasar de puntiIlas" en estos temas, rebajando la tensión que crean los abogados catalanes en plena campaña electoral, al aprobar que el catalán sea la lengua oficial en todas las profesiones jurídicas. Otros asuntos que tratan de ser soslayados son la aplicación del llamado "decreto del cine". También la decisión del Gobierno central de plantear un conflicto positivo de competencias ante el Tribunal Constitucional, en respuesta al acuerdo tomado por la Generalitat de Cataluña, por su decisión de conceder una paga extraordinaria para los perceptores de pensiones no contributivas en Cataluña.

5 Vid. Alonso de los Rios, A. "Se vota Estado", en ABC (5-10-1999).

6 Resulta muy ilustrativo, por el alto nivel alcanzado, el debate originado sobre este tema y las réplicas publicadas en El País por dos grandes personalidades: Solé TURA, J. «El federalismo y nuestro futuro» (7-10-1999). HerRero de Miñón, M. "¿Panacea federal?" (2-11-1999). Solé TURA, J. «Un federalismo sin panaceas" (2011-1999).

7 Durante la campaña el candidato de ERC, Josep Lluís Carod-Rovira, volvió a su discurso tradicional basado en la independencia de Cataluña "o la capacidad de decidir por nosotros mismos", en El País (8-10-1999). 
CUADRO 1

RENTA FAMILIAR DISPONIBLE POR HABITANTE ${ }^{8}$

\begin{tabular}{clcc}
\hline $\begin{array}{c}\text { Nivel } \\
\text { económico }\end{array}$ & $\begin{array}{c}\text { Intervalos } \\
\text { en pesetas }\end{array}$ & $\begin{array}{c}\text { \% de habitantes } \\
\text { en España }\end{array}$ & $\begin{array}{c}\% \text { de habitantes } \\
\text { en Cataluña }\end{array}$ \\
\hline 1 & $0-900.000$ & $(1,09 \%)$ & - \\
2 & $900.000-1.000 .000$ & $(4,09 \%)$ & - \\
3 & $1.000 .000-1.125 .000$ & $(14,24 \%)$ & - \\
4 & $1.125 .000-1.250 .000$ & $(17,70 \%)$ & $(0,02 \%)$ \\
5 & $1.250 .000-1.400 .000$ & $(14,91 \%)$ & $(0,96 \%)$ \\
6 & $1.400 .000-1.600 .000$ & $(22,27 \%)$ & $(49,62 \%)$ \\
7 & $1.600 .000-1.800 .000$ & $(21,19 \%)$ & $(40.01 \%)$ \\
8 & $1.800 .000-2.000 .000$ & $(3,08 \%)$ & $(4,27 \%)$ \\
9 & $2.000 .000-2.200 .000$ & $(1,34 \%)$ & $(4,65 \%)$ \\
10 & $2.200 .000-0$ más & $(0,09 \%)$ & $(0,47 \%)$ \\
\hline
\end{tabular}

Fuente: Anuario Comercial de España 1999. La Caixa.

Por eso la acumulación de la renta familiar se produce, en el caso de Cataluña, casi exclusivamente en la zona media del gráfico -o si realizamos la traslación, en una posición de centro en términos políticos--, es decir, que en Cataluña la mayoría de la población se sitúa, en cuanto a ingresos, dentro de la clase media, no detectándose estadísticamente un gran número de pobres, pero tampoco de ricos ${ }^{9}$.

Sin duda, los dos grandes partidos políticos catalanes, CiU y PSC, tratan de dirigir la búsqueda de votos en esta dirección. CiU tratando de rentabilizar la bonanza económica que está viviendo Cataluña, con un desempleo claramente inferior a la media española, con una demanda de mano de obra creciente en las industrias de transformación y de servicios, pero también con disfunciones del sistema como

8 Población total de Cataluña: 6.147.610. De España: 39.323.320. De la Unión Europea: 373.300 .000 .

9 Durante la legislatura el hecho más brillante es el descenso del desempleo del $17 \%$ al $10,4 \%$, muy por debajo de la media española del $15,63 \%$, y a un nivel similar al de Alemania (10,1\% o Francia (10,2\%). El País (14-10-1999). 
las bolsas de miseria que se ocultan tras las estadísticas, y con otro asunto espinoso que representa la situación de los inmigrantes.

No obstante, hay que reconocer que $\mathrm{CiU}$ ha sabido hacer valer, frente a su electorado, el hecho de tener asegurado más del $16 \%$ de la inversión del Estado en Cataluña para los próximos años. De esta forma, proyectos en marcha tan importantes como los del AVE, la ampliación del aeropuerto y del puerto o el desvío del río Llobregat, se podrán prolongar sin problemas presupuestarios durante años.

\section{LOS PRONÓSTICOS ELECTORALES}

Curiosamente los pronósticos electorales no se cumplieron, en un sentido inverso al de las primeras elecciones autonómicas del año 1980, en las que CiU dio la sorpresa al obtener más escaños que los que le asignaban las encuestas electorales publicadas ${ }^{10}$. En esta ocasión, al contrario que entonces, las encuestas preelectorales, publicadas por la prensa hasta el domingo anterior al 17 de octubre de 1999, daban al partido Convergència i Unió una victoria con soltura [ver gráfico 2], para ir decayendo e imponerse apuradamente en los sondeos realizados a pie de urna [ver gráfico 3]. La realidad del escrutinio rebajó todavía más las expectativas de CiU, demostrando la sensible desviación de las encuestas sobre los resultados reales, siendo los sondeos a pie de urna, realizados por empresas contratadas por radios y televisiones, las que más se ajustaron al resultado final.

10 Ollero Butler, F. “Elecciones al Parlamento Catalán», en Revista del Departamento de Derecho Político, núm. 6. Primavera, 1980. pág. 182. Del mismo autor vid. "El referéndum para la autonomía de Cataluña", en Revista del Departamento de Derecho Político, núm. 5. 1980. págs. 213-225. 


\section{CUADRO 2}

\section{LAS ENCUESTAS PREELECTORALES}

Previsión de escaños y, entre paréntesis, porcentaje de voto de los sondeos electorales de los principales diarios.

\begin{tabular}{lrrrrrr}
\hline $\begin{array}{l}\text { Partidos } \\
\text { y coaliciones }\end{array}$ & CiU & PSC-CC* & PP & ERC & IC-V** & EUIA \\
\hline VOTO REAL & $56(37,71 \%)$ & $52(37,85 \%)$ & $12(9,51 \%)$ & $12(8,69 \%)$ & $3(2,51 \%)$ & $-(1,42 \%)$ \\
\hline Empresa ${ }^{11:}$ & & & & & & \\
DYM & $57-63(40,5 \%)$ & $40-46(30,3 \%)$ & $14-15(11,3 \%)$ & $12-15(9,7 \%)$ & $5-6(5,6 \%)$ & $0(2,0 \%)$ \\
CIS & $57-59(38,6 \%)$ & $45-47(31,7 \%)$ & $14-15(11,5 \%)$ & $11-13(9,7 \%)$ & $4-5(4,5 \%)$ & $-(-)$ \\
DEMOSCOPIA & $58-60(40,1 \%)$ & $48-50(36,6 \%)$ & $13-14(10,7 \%)$ & $10(7,7 \%)$ & $3(3,2 \%)$ & $0(1,5 \%)$ \\
OPINA & $56-58(39,0 \%$ & $151-52(36,0 \%)$ & $13(10,5 \%)$ & $9-10(7,5 \%)$ & $4(4,0 \%)$ & $0(1,5 \%)$ \\
IPSOS-ECOCON & $53-55(37,2 \%)$ & $45-47(32,9 \%)$ & $15-16(12,1 \%)$ & $12-13(8,9 \%)$ & $7-8(6,7 \%)$ & $-1-1$ \\
SULTING & & & & & & \\
SIGMA 2 & $58-62(40,4 \%)$ & $48-50(35,7 \%)$ & $12-14(10,2 \%)$ & $10(7,7 \%)$ & $3(2,6 \%)$ & $0(1,5 \%)$ \\
\hline
\end{tabular}

* En Girona, Lleida y Tarragona incluye a IC-V.

* Resultados obtenidos sólo en la provincia de Barcelona.

Fuente: La Vanguardia (18-10-1999).

En el gráfico número 2, podemos comparar las últimas encuestas encargadas por los principales diarios, y la encuesta del Centro de Investigaciones Sociológicas $(\mathrm{CIS})^{12}$, que colocaban a la coalición de Jordi Pujol en una horquilla de entre el $40 \%$ y el $40,5 \%$ de los votos ${ }^{13}$, o muy cercana a estas cifras $^{14}$, situando a Convergència i Unió muy próxima a los diputados alcanzados en la pasada legislatura e incluso por encima de los 60 escaños.

Además, las encuestas seguían reflejando cifras bastante benignas para CiU, después de no prever el descalabro de la coalición de Pujol en la ciudad de Barcelona en las pasadas elecciones municipales de junio. No obstante, donde todas las encuestas acertaron, fue

11 Los diarios que encargaron estas encuestas -con la respectiva empresa entre paréntesis-, son: El Periódico (Dym); la encuesta del Centro de Investigaciones Sociológicas CIS, es oficial; El País (Demoscopia); La Vanguardia (Opina); ABC (Ipsos-Ecoconsulting) y EI Mundo (Sigma 2).

12 La encuesta del CIS se publicó en $A B C$ (8-10-1999). Cfr. «El sondeo del CIS", en $A B C$ (9-10-1999).

13 Las empresas que realizaron este pronóstico fueron Dym para El Periódico, Sygma 2 para EI Mundo y Demoscopia para EI País.

14 Las empresas que se acercaron al pronóstico de resultados de la nota 13, fueron Ipsos-Eco Consulting para $A B C$ y Opina para La Vanguardia. 
en que la formación electoral de Antonio Luchetti, coordinador general de Esquerra Unida i Alternativa (EUiA), el referente de Izquierda Unida en Cataluña, se quedaría sin representación parlamentaria.

Por otro lado, las encuestas habían pronosticado peores resultados de los obtenidos para la coalición encabezada por Pasqual Maragall15. Estas distorsiones primaban claramente a CiU, con la excepción del trabajo de Ipsos-Eco Consulting encargado por $A B C$, que se acercó en el porcentaje de votos, pero que se quedó corto en el número de escaños ${ }^{16}$. En la difícil técnica de la previsión electoral, sólo los resultados de los sondeos a pie de urna [ver cuadro 3], encargados por algunas cadenas de televisión, y por razones obvias de clarificación del voto el mismo día de la elección, se acercaron más a lo que finalmente fueron los resultados oficiales.

\section{CUADRO 3 \\ SONDEOS A PIE DE URNA ${ }^{17}$}

\begin{tabular}{lcccccc}
\hline $\begin{array}{l}\text { Partidos Y } \\
\text { coaliciones }\end{array}$ & CiU & PSC-CC* & PP & ERC & IC-V** & Euia \\
\hline $\begin{array}{l}\text { Diputados } \\
\text { alcanzados }\end{array}$ & 56 & 52 & 12 & 12 & 3 & 0 \\
$\begin{array}{l}\text { Empresas } \\
18 \text { : }\end{array}$ & & & & & & \\
$\begin{array}{l}\text { Eco-Consulting } \\
\text { Opitel }\end{array}$ & $55-57$ & $50-52$ & $12-14$ & $11-13$ & $3-4$ & - \\
Sigma 2 & $57-58$ & $50-52$ & $11-12$ & $10-12$ & 4 & - \\
\hline
\end{tabular}

* En Girona, Lleida y Tarragona incluye a IC-V.

** Resultados obtenidos sólo en la provincia de Barcelona

Fuente: La Vanguardia (18-10-1999).

15 Las encuestas que más se acercaron a los resultados finales fueron: EI País que le adjudicaba el $36,6 \%$ de los votos, con un máximo de 50 escaños, y La Vanguardia, con el $36 \%$ de los votos y un máximo de 52 escaños. escaños.

${ }_{16}$ Esta empresa asignaba un $37,2 \%$ a CiU, con una horquilla entre 53 y 55

17 Previsión de los escaños que dieron las principales cadenas de televisión al cierre de las urnas.

18 Las cadenas de televisión que encargaron este trabajo, con su respectiva empresa en paréntesis, son: TV-3 y TVE (Eco-Consulting); Tele 5 (Opitel); Antena3 TV (Sigma 2). 
No obstante, esto no hace más que poner de relieve las dificultades encontradas para una previsión electoral a medio y corto plazo que resulte más precisa. Un editorial del periódico $A B C$ podría sintetizar la frustración ante la "escasa fiabilidad" en estos comicios de las encuestas, bien porque "los electores parecen haber renunciado a la sinceridad para contestar a los encuestadores sobre la verdadera orientación de su voto", o bien porque se alejan del "desideratum al que no han apoyado con sus papeletas" ${ }^{19}$. No obstante, los dirigentes de CiU ya habian tomado buena cuenta de no repetir los errores de las elecciones de 1995, cuando las encuestas les daban también la victoria, incluso rozando la mayoria absoluta, para posteriormente en el recuento de votos perder 10 diputados. Por eso, ya en el último consejo nacional de Convergència, el 12 de septiembre, se había alertado "contra las encuestas" y se había llamado a la militancia para que movilizaran al electorado más fiel.

\section{VOTOS VERSUS ESCAÑOS}

La noche del domingo 17 de octubre de 1999, día de la votación, deparó un recuento de votos que fue calificado por casi todos los medios informativos "de infarto", por lo contradictorio de los resultados provisionales que se nos iban ofreciendo, muy variables según el momento en que se daban a conocer los datos disponibles. Las mayorías se consolidaban y se perdían en cuestión de minutos, y un solo diputado separaba a las dos principales formaciones electorales. La prensa se hacía eco de la noche de incertidumbre que nos habían deparado las elecciones autonómicas del presente año, sin duda sin parangón antes en Cataluña, y lo apurado de la victoria de Jordi Pujol sobre un rival político de envergadura como Pasqual Maragall.

Por otro lado, las valoraciones de los comicios al día siguiente no pueden poner más de relieve la compleja situación en la que ha quedado la gobernabilidad de Cataluña. Así El Periódico de Catalunya expresa en titulares la conflictiva situación, con la frase en portada: "Jordi Pujol gana en escaños. Maragall, en votos" ${ }^{20}$.

¿Cómo es posible ganar en escaños, si se pierde en número total de votos? Empecemos centrando nuestra atención sobre los datos dis-

$19 \mathrm{ABC}(18-10-1999)$.

20 El Periódico de Catalunya (18-19-1999). 
ponibles: la coalición encabezada por Maragall PSC-Ciutadans pel Canvi, había logrado cerca de 5.000 votos de diferencia sobre CiU, después de sumar todas las diferentes modalidades de coalición del PSC con Ciutadans pel Canvi en el conjunto de Cataluña y con IC-Verds en todas las provincias, menos en Barcelona.

No obstante, CiU, a pesar de haber obtenido menos votos que la coalición de Maragall, se alzaba con la victoria en estos comicios, por la mínima diferencia de un diputado. De esta forma, la coalición de Maragall había obtenido 52 escaños, a los que se sumarían los tres que Iniciativa per Catalunya (IC) había conseguido en Barcelona. Frente a estos resultados, y por un ajustado margen de diferencia, el partido de Pujol había obtenido 56 diputados, por lo que alcanzaba por sexta vez consecutiva el éxito en las elecciones autonómicas catalanas, a la vez que se abría para Ciu, de nuevo, la formación del próximo gobierno de la Generalitat.

La explicación de esta situación de aparente "empate técnico", que representa una de las menores diferencias que se han dado en las elecciones celebradas en nuestro país, y que a la vez supone un hecho muy curioso en la historia de la democracia española -por la constatación de que se puede ganar en votos, aunque por una mínima diferencia, pero perder en escaños-, la tenemos en el sistema electoral.

Efectivamente, Duglas Rae y Victoriano Ramírez ya habían explicado hace tiempo que el sistema electoral, puede ser imparcial, y por tanto un sistema legítimo -ya que no puede ser manipulado contra un partido concreto-, pero que no por eso se está exento de riesgos, puesto que la imparcialidad del sistema no implica necesariamente "que el mismo porcentaje del voto nacional produce invariablemente el mismo porcentaje de escaños legislativos, es el caso de un partido que divide estratégicamente su fuerza de modo a ganar muchos escaños, mientras otro, con el mismo porcentaje, desperdicia muchos votos y consigue pocos escaños" ${ }^{21}$.

No obstante, afinando todavía más en nuestro sistema electoral, comprobaremos, según los estudios científicos de los que disponemos, -como también ya se ha encargado de demostrar la experiencia en España- que uno de los factores que más inciden sobre

21 RaE, D; Ramirez, V. El sistema electoral español (Quince años de experiencia). Madrid, 1993. pág. 6. Rae, D. Leyes electorales y sistema de partidos politicos. Madrid, 1977. pág. 189. 
las fórmulas electorales gira en torno al tamaño de los distritos electorales ${ }^{22}$.

En el análisis del sistema electoral el objeto de estudio será básicamente común, dado que en España las Comunidades Autónomas pueden ejercer sus competencias en materia electora ${ }^{23}$, pero teniendo presente la Ley Orgánica 5/1985, de 19 de junio, del Régimen Electoral General (LOREG), que establece las condiciones básicas para su ejercicio, que fueron dictadas por el Estado en virtud del artículo 149.1.1 $\mathrm{CE}^{24}$. Por eso, ninguna ley electoral autonómica puede contradecir la normativa electoral, o convertirla en puro derecho supletorio de sus respectivas leyes, tal y como el Tribunal Constitucional ha declarado en sus Sentencias STC 75/1985 y STC 154/198825.

De esta forma, tenemos el problema del tamaño de los distritos, cuyos efectos sobre los resultados son bastante conocidos a nivel estatal, cuando en las elecciones al Congreso de los Diputados, nos encontrába-

22 Son muchos los autores que recogen, dentro de sus estudios sobre los sistemas electorales, la incidencia de la naturaleza y magnitud de los distritos electorales sobre los mismos. Por citar sólo algunos: BLAIS, A. "The classification of electoral Systems", en European Journal of Political Research, n. ${ }^{\circ} 9$, 1988. pág. 108. LIJPHART, A; GrofmAn, B (eds). Electoral laws and their political consequences. New York, 1986. Nohlen, D. Sistemas electorales del mundo. Madrid, 1981. VALLÉS, J. M. "Sistema electoral y reprentativa: Nota sobre la Ley Orgánica de Régimen Electoral General de 1985 y su función política», en Revista de Estudios Políticos, núm. 53, 1986.

${ }^{23}$ En Cataluña las normas que regulan los procedimientos electorales son: Ley Orgánica 4/1979, de 18 de diciembre, del Estatuto de Autonomía de Cataluña. Ley 3/1982, de 23 de marzo (BOE de 4 de mayo 1982). Ley 23 de marzo 1982, núm. 3/82 (Generalidad de Cataluña). Normas reguladoras del Parlamento y del Presidente y Consejo Ejecutivo de la Generalidad (BOE 4 de mayo 1982). Ley 24 de mayo 1985, núm 8/85 (Generalidad de Cataluña). Modificación de la Ley 23 de marzo de 1982, del Parlamento, del Presidente y del Consejo Ejecutivo de la Generalidad (BOE de 2 de agosto 1985). Ley $5 / 1984$, de 5 de marzo, por la que se adapta la normativa general electoral para las elecciones al Parlamento de Cataluña de 1984 (DOGC n. 414, de 7 de marzo de 1984). Ley 16/1990, de 13 de julio, sobre el régimen especial del Valle de Arán (DOGC n.' 1.326, de 3 de agosto de 1990).

${ }^{24}$ García Soriano, M. V. Elementos de Derecho Electoral. Valencia, 1999. pág. 34.

25 La STC 75/1985 dice: «no puede aceptarse que el Estatuto de Autonomía (... convierta a las normas electorales estatales en puro derecho supletorio, no aplicable, por tanto, ante las normas inmediatamente operativas que se quieren ver en el apartado (... del Estatuto". La STC 154/1988, expresa: "La C.A (... al ejercer su competencia en materia electoral, ha de tener presente, en primer lugar, las normas estatales de desarrollo del derecho de sufragio reconocido en el art. $23 \mathrm{CE}$, así como las que regulen las condiciones básicas que garanticen la igualdad en el ejercicio del mismon. 
mos también con diferencias del cociente población/escaño del orden de 4 a 1, que favorecen claramente a ciertos distritos -el caso clásico que se suele poner es el de Soria-, en detrimento de otros más poblados como Madrid o Barcelona. La argumentación anterior resulta, por tanto, extrapolable también en Cataluña, donde encontramos que en las elecciones autonómicas, no "vale» igual un voto en la circunscripción electoral de Barcelona, que, por citar otros lugares, en Girona, Lleida o Tarragona, de manera que el reparto en ciertos casos resultará igualmente desigual, si ponemos la población en relación al tamaño de los distritos.

Si tomamos, por ejemplo, la circunscripción electoral de BarceIona, que posee el $76 \%$ de los electores con derecho a voto, y consideramos como base del reparto los 135 escaños que componen el Parlament de Cataluña -de forma que resulte proporcional a los electores-, entonces corresponderían de esta forma a esta circunscripción 102 escaños, pero en realidad sólo tiene 85 escaños. Considerando el caso contrario, si centramos nuestra atención en la circunscripción electoral de Lleida, donde tiene derecho a voto casi el $6 \%$ del total de los votantes, nos encontramos que esto significaría sólo 7 escaños para la provincia, cuando en realidad posee 15 escaños.

De lo anterior resulta claramente deducible que Barcelona, según este reparto de escaños, se encuentre "infrarepresentada», mientras que Lleida por el contrario esté "sobrerepresentada", pues obtener un parlamentario en Lleida, por ejemplo, requiere unos 12.000 votos, mientras que en Barcelona son necesarios más de $27.000^{26}$. De esta forma, atendiendo al tamaño de los distritos, podemos explicar en buena medida, que CiU, que tiene mayor implantación en toda Cataluña, obtenga más escaños con menos votos.

No obstante, la posibilidad de que una candidatura gane la elección en escaños a pesar de no ser la más votada, no es un hecho privativo de nuestro país, de nuestras circunscripciones, ni siquiera de nuestro sistema electoral proporcional. De esta forma, encontramos también un desfase entre votos y representatividad en el Reino Unido, que con un sistema electoral mayoritario a una vuelta en distritos uninominales, reproduce en varias ocasiones esta situación -los laboristas en 1945 y $1974^{27}$ y los conservadores en 1959 y 1984-.

26 Cfr. La Vanguardia (18-10-1999).

27 En 1974, el laborista Harold WILSON obtuvo 301 escaños con el $37 \%$ de los votos, frente al conservador Edward Heath, al que se le asignó 287 diputados con el $38,2 \%$ de los sufragios. HEALTH intentó formar un gobierno de coalición con el líder liberal Jeremy THORPE, pero al no conseguirlo fue finalmente Wilson el que a 
En los Estados Unidos, con un sistema de elección indirecta del presidente, en dos ocasiones los candidatos electos no fueron tampoco los más votados ${ }^{28}$.

\section{PARTICIPACIÓN}

El día de la jornada electoral transcurrió sin incidentes de consideración ${ }^{29}$, lo más destacado fue lo adverso de la climatología, que según el consejero de Gobernación, Xavier Pomés, pudo incidir en una baja participación ${ }^{30}$ cifrada en un $59,92 \%$, -según los datos definitivos de la Conselleria de Gobernación-, lo que supone un retroceso de 3,72 puntos menos que en las elecciones autonómicas de noviembre de 1995.

Según se puede ver gráficamente en el cuadro 4 -niveles de participación en las elecciones autonómicas catalanas-, la participación registrada en octubre de 1999 es la tercera más baja en los seis comicios al Parlament celebrados desde la recuperación de la autonomía en 1980.

Tal y como se puede apreciar en el cuadro 4, los comicios de 15 de marzo de 1992 -el año de las Olimpiadas- fueron los de menor participación $(54,9 \%)$, pues estaban convocados a votar 4.838 .722 votantes y faltaron a su cita con las urnas más de dos millones de electores. De forma inversa, los comicios que experimentaron un grado de participación más elevado en Cataluña fueron los de 29 de abril de 1984, con un $64,3 \%$.

pesar de tener menos votos pero teniendo más escaños, formó finalmente gobierno. Vid. El Periódico de Catalunya (19-10-1999).

${ }_{28} \quad$ Los presidentes en cuestión que no fueron los más votados pero que terminarían ocupando la Casa Blanca, fueron los republicanos Rutherford B. Hayes, en 1876 y Benjamin Harrison, en 1888.

29 Grupos de "okupas" y autodenominados "antifascistas" habían convocado una manifestación el día 12 de octubre, en la que se provocaron incidentes. Durante las últimas 48 horas de la campaña electoral habian intensificado su cam. paña de atentados con cócteles molotov, produciéndose cinco atentados con artefactos incendiarios contra el Cuerpo Nacional de Policía, el PP y sucursales bancarias de escasas consecuencias. El Mundo (18-10-1999).

30 Sobre la baja participación quizá pudo incidir la lluvia, que cayó en Cataluña de forma intermitente a lo largo de toda la jornada electoral, acentuándose al anochecer. El País (18-10-1999). 


\section{CUADRO 4 \\ NIVELES DE PARTICIPACIÓN (\%) EN LAS ELECCIONES AUTONÓMICAS CATALANAS}

\begin{tabular}{|c|c|c|c|c|c|c|}
\hline $\begin{array}{l}\text { Fecha de la } \\
\text { elección }\end{array}$ & $\begin{array}{c}20 \text { mayo } \\
1980\end{array}$ & $\begin{array}{c}29 \text { abril } \\
1984\end{array}$ & $\begin{array}{c}29 \text { mayo } \\
1988\end{array}$ & $\begin{array}{c}15 \text { marzo } \\
1992\end{array}$ & $\begin{array}{c}19 \text { noviemb } \\
1995\end{array}$ & $\begin{array}{r}17 \text { octubre } \\
1999\end{array}$ \\
\hline Censo & 4.392 .298 & 4.521 .300 & 4.564 .389 & 4.838 .722 & 5.029 .727 & 5.205 .109 \\
\hline $\begin{array}{l}\text { Participa- } \\
\text { ción }(\%)\end{array}$ & 62,1 & 64,3 & 59,4 & 54,9 & 63,6 & 59,9 \\
\hline Abstención & 1.658 .475 & 1.628 .373 & 1.854 .704 & 2.183 .671 & 1.811 .639 & 2.126 .292 \\
\hline Abstención (\%) & 37,9 & 36,1 & 40,6 & 45,1 & 36,3 & 40,0 \\
\hline
\end{tabular}

Fuente: Elaboración propia utilizando datos publicados en La Razón (18-10-1999)

y El País (18-10-1999).

Comparando los niveles de abstención del cuadro 4 -a nivel autonómico-con los del cuadro 5 -a nivel estatal-, vemos que la abstención continúa siendo alta en los comicios autonómicos, frente al descenso al 22,20 de las últimas elecciones generales.

Los índices de abstención en Cataluña -al igual que en las elecciones autonómicas en el País Vasco, Galicia o Andalucía- se pueden considerar altos, al superar medias del $30 \%$, llegando a rebasar en algunos casos incluso el $40 \%$, como en las ya citadas elecciones autonómicas catalanas de 1992.

\section{CUADRO 5}

EVOLUCIÓN DE LA ABSTENCIÓN EN LAS ÚLTIMAS ELECCIONES GENERALES ESPAÑOLAS

\begin{tabular}{lcccc}
\hline Elecciones & 1986 & 1989 & 1993 & 1996 \\
\hline abstención & 8.619 .801 & 8.970 .431 & 7.030 .680 & 7.124 .476 \\
\hline \hline$\%\rangle$ & 30,00 & 30,00 & 22,90 & 22,20 \\
\hline
\end{tabular}

Fuente: La Razón (19-10-1999).

Precisamente la abstención o, en sentido contrario, la participación fue uno de los elementos más destacados durante la campaña 
electoral, en el convencimiento, avalado por algunos estudios electorales $^{31}$, de que un alto grado de participación podía beneficiar a los socialistas, cuyo electorado natural suele participar en mayor proporción cuando se trata de elecciones generales, razón por la que el PSC hizo un esfuerzo de captación en el área metropolitana de Barcelona ${ }^{32}$.

En cualquier caso, una abstención alta del $40 \%$ es un mal dato, como pone de relieve el catedrático de Sociología de la Universidad Complutense de Madrid, Juan Diez Nicolás. Para este autor la abstención, además de ser elevada, confirma un temor: "El electorado está dando claros signos de aburrimiento y desencanto"; el problema es que este desinterés perjudica claramente a la democracia, pues uno de sus pilares, como resulta obvio, es la participación de los ciudadanos en los asuntos públicos ${ }^{33}$.

Por eso, dejando atrás conveniencias partidistas, la abstención resulta especialmente preocupante, en nuestra opinión, máxime cuando la despreocupación del electorado en el ámbito autonómico se produce cuando está a punto de equipararse el reparto del control del gasto público entre la Administración central y las territoriales -que en la actualidad se distribuye en un $55 \%$ para la primera y en un 45\% para las segundas-. En el año 2004 se culminará el proceso de traspasos de competencias desde la Administración Central a las distintas Comunidades Autonómas, una vez que las llamadas Comunidades de "vía lenta" han conseguido acercarse a las llamadas de "vía rápida".

Todo esto ocurre con ese preocupante desinterés del $40 \%$ del electorado catalán, cuando España se encuentra entre los países más descentralizados del mundo y se trata de elegir a las personas que van a tener la oportunidad de ejercer la responsabilidad y negociar sus intereses frente a los responsables del Gobierno central.

\section{LOS RESULTADOS ELECTORALES}

La sexta victoria consecutiva de la coalición de Jordi Pujol supone un hecho muy curioso dentro de las democracias europeas de nues-

31 Vid. El Mundo (17-10-1999)

32 En el área metropolitana de Barcelona se localiza una parte del electorado que tiene orígenes inmigrantes.

${ }^{33} A B C$ (19-10-1999). 
tro entorno, entre otras razones, por la posibilidad para el político catalán -si apura la legislatura- de mantenerse 23 años al frente de la Generalitat de Cataluña, superando incluso la marca de algunos de los más destacados mandatarios europeos como Margaret Thatcher en Gran Bretaña o Helmut Khol en Alemania. No obstante, el éxito electoral para $\mathrm{CiU}$ no oculta que los resultados que han obtenido en las elecciones del 17 de octubre de 1999, tal y como se puede ver en el cuadro 6 , son los peores en el ámbito autonómico para la centroderecha de Pujol desde 1984, después del aviso de los 773.826 votos obtenidos en las municipales de 1999 [ver cuadro 7].

CUADRO 6

EVOLUCIÓN DEL VOTO AUTONÓMICO DE CIU

\begin{tabular}{lcccccc}
\hline Elecciones & 1980 & 1984 & 1988 & 1992 & 1995 & 1999 \\
\hline N. de votos & 754.788 & 1.347 .037 & 1.232 .514 & 1.221 .233 & 1.320 .07 & 11.178 .420 \\
\hline Porcentaje & 27,8 & 46,8 & 45,7 & 46,2 & 40,9 & 37,7 \\
\hline
\end{tabular}

Fuente: La Vanguardia (18-10-1999).

El retroceso electoral de CiU ha ido acompañado del espectacular avance de la coalición de Pasqual Maragall, que ha conseguido elevar su cuota electoral desde los 802.252 votos de las elecciones autonómicas de 1995, hasta 1.183.299 votos alcanzados en los comicios de octubre de 1999. Esta evolución del voto se puede apreciar en el cuadro 7, que recoge las citas electorales más recientes en Cataluña, mostrando la evolución y la diversidad del comportamiento electoral según el tipo de elecciones.

El cuadro número 7 nos permite apreciar también lo que algunos estudiosos de los comicios catalanes denominan el "voto dual", en referencia al fenómeno electoral que muestra que cierto sector de los ciudadanos catalanes prefieren respaldar a $\mathrm{CiU}$ en las elecciones autonómicas - por ejemplo, en las autonómicas de 1995, CiU obtuvo 1.320.071 votos frente a los 802.253 de los socialistas-; mientras en las elecciones generales salen beneficiados los socialistas -por ejemplo, en las generales de 1996, el PSC obtiene 1.531.143 votos frente a CiU, que sólo alcanza 1.151.633-. 


\section{CUADRO 7 \\ EVOLUCIÓN DEL VOTO EN CATALUÑA}

\begin{tabular}{lccccc}
\hline & $\begin{array}{c}\text { Autonómicas } \\
1999\end{array}$ & $\begin{array}{c}\text { Municipales } \\
1999\end{array}$ & $\begin{array}{c}\text { Europeas } \\
1999\end{array}$ & $\begin{array}{c}\text { Generales } \\
1996\end{array}$ & $\begin{array}{c}\text { Autonómicas } \\
1995\end{array}$ \\
\hline $\mathrm{PSC}\left(^{*}\right)$ & 1.183 .299 & 1.089 .965 & 991.656 & 1.531 .143 & 802.252 \\
\hline $\mathrm{CiU}$ & 1.178 .420 & 773.826 & 839.693 & 1.151 .633 & 1.320 .071 \\
\hline $\mathrm{PP}$ & 297.265 & 319.091 & 484.204 & 698.400 & 421.752 \\
\hline $\mathrm{ERC}$ & 271.173 & 223.929 & 173.595 & 162.545 & 305.867 \\
\hline $\mathrm{IC}$ & $\left.78.4411^{* *}\right)$ & 186.394 & 156.002 & 296.985 & 313.092 \\
\hline EUiA & 44.454 & 57.812 & 58.535 & - & - \\
\hline
\end{tabular}

(*) En las últimas elecciones autonómicas de 1999, el PSC Partit dels Socialistes de Catalunya, ha ido coaligado con Ciutadans pel Canvi CPC, Iniciativa per Catalunya IC, y Verds V, en Lleida, Tarragona y Girona. En Barcelona ha formado coalición el PSC, con ciutadans pel Canvi.

${ }^{* *}$ ) Son los votos de Iniciativa per Catalunya IC-Verds únicamente en Barcelona.

Fuente: Elaboración sobre datos oficiales facilitados por la Generalitat de Cataluña y publicados en el Diari Oficial de la Generalitat de Catalunya, núm. 3007, de 3 de diciembre de 1999. Otros datos, en La Vanguardia, de 18 de octubre de 1999.

Por otro lado, el tipo de elección también va a condicionar el nivel de participación - del cual nos hemos ocupado anteriormente-, pues hay que tener en cuenta que se suele elevar el número de votos en las generales, al despertar un mayor interés en el electorado sobre otros tipos de elecciones.

Por citar un caso concreto que nos permita apreciar esta tendencia, una década antes de las elecciones del 17 de octubre, nos referiremos al año 1988, en el que se celebraron las elecciones autonómicas catalanas de 29-5-1988, a las que concurrieron 2.713 .129 votantes, un $59,5 \%$ del electorado. En el año 1989, se celebraron las elecciones europeas de 15-6-1989, a las que concurrieron en Cataluña 2.399.048 votantes, bajando la participación en dicha Comunidad Autónoma al 51,5\% -es decir 8 puntos porcentuales menos que las autonómicas-. $Y$ en las generales de 28-10-1989, habían concurrido en Cataluña 3.175.905 votantes, un $67,6 \%$, lo que representaba que dentro de Cataluña había una diferencia, entre estas últimas elecciones generales de 16,1 puntos más que las europeas y de un 8,1 más que las autonómicas ${ }^{34}$.

34 Datos de la Junta Electoral Central. «Participación electoral en España: 1977-1989", en Revista del Centro de Estudios Constitucionales. Núm. 6. Mayo- 
Por tanto, la cuestión de las diferencias de participación, y que vote un $15 \%$ más del electorado, como sucedió en aquel caso, puede representar una alteración significativa de los resultados electorales, será una de las múltiples cuestiones que tendrá que ser debidamente valorada a la hora de interpretar globalmente el cuadro número 7.

Centrándonos más propiamente en los resultados de las elecciones del pasado 17 de octubre [ver cuadro 8], realizaremos un análisis particularizado de la distribución del voto en las cuatro provincias catalanas, empezando por la más poblada, que es Barcelona.

\section{CUADRO 8}

Partidos que concurren en las elecciones catalanas de 1999 y porcentaje (\%) de voto

\begin{tabular}{|c|c|c|c|}
\hline Siglas & $\%$ Votos & Escaños & Nombre completo del Partido \\
\hline CiU & $(37,68)$ & 56 & Convergència i Unió \\
\hline $\begin{array}{l}\text { PSC-CPC- } \\
\text { IC-V }\end{array}$ & $(37,88)$ & 52 & $\begin{array}{l}\text { Partit dels Socialistes de Catalunya- } \\
\text { Ciutadans pel Canvi - Iniciativa per- } \\
\text { Catalunya - Verds }\end{array}$ \\
\hline$P P$ & $(9,51)$ & 12 & Partit Popular \\
\hline ERC & $(8,68)$ & 12 & Esquerra Republicana de Catalunya \\
\hline IC-V & $(2,51)$ & 3 & Iniciativa per Catalunya - Verds \\
\hline EUiA & $(1,43)$ & - & Esquerra Unida i Alternativa \\
\hline EV-CEC & $(0,71)$ & - & $\begin{array}{l}\text { Els Verds - Confederació Ecologista } \\
\text { de Catalunya }\end{array}$ \\
\hline EV-AV & $(0,26)$ & - & Els Verds Alternativa Verda \\
\hline E.C. & $(0,07$ & - & Estat Català \\
\hline POSI & $(0,06)$ & - & $\begin{array}{l}\text { Partido Obrero Socialista Interna- } \\
\text { cionalista }\end{array}$ \\
\hline FE-JONS & $(0,04)$ & - & Falange Española y de las Jons \\
\hline $\mathrm{PHC}$ & $(0,04)$ & - & Partido Humanista de Cataluña \\
\hline UC-CDS & $(0,03)$ & - & $\begin{array}{l}\text { Unión Centrista - Centro Democrá- } \\
\text { tico y social }\end{array}$ \\
\hline
\end{tabular}

agosto 1990. pág. 418-419. Cfr. Datos oficiales de las Juntas Electorales Provinciales, de las elecciones al Parlamento europeo de 1989, en BOE de 6 de junio de 1989, $y$ de 1994, en BOE de 30 de junio de 1994. 


\section{CUADRO 8}

Partidos que concurren en las elecciones catalanas de 1999 y porcentaje (\%) de voto (Continuación)

\begin{tabular}{lccl}
\hline Siglas & $\%$ Votos & Escaños & Nombre completo del Partido \\
\hline PLN & $(0,03)$ & - & Partit de la Llei Natural \\
UNIC-FIC & $(0,03)$ & - & $(*)$ \\
TPR & $(0,03)$ & - & Trabajadores Públicos Rebotados \\
PE & $(0,03)$ & - & Partit Espinalti \\
LIT-CI & $(0,02)$ & - & Lluita Internacionalista \\
U.F.D. & $(0,01)$ & - & Unión Federal Democrática \\
PDEP & - & - & Partido Democrático del Pueblo \\
CAM & - & - & Catalans al Món \\
\hline
\end{tabular}

Fuente: Diari Oficial de la Generalitat de catalunya. Núm 3007, (3-11-1999). Otros datos en La Razón (19-10-1999).

(*) En los datos oficiales solamente aparece en la circunscripción de Tarragona, siendo el único partido de esa circunscripción, que aparece en siglas sin el nombre completo.

En el cuadro 9, -que está elaborado sobre datos oficiales proporcionados por la Generalitat-podemos comprobar que la coalición de Pasqual Maragall logra lo que parecía imposible: ganar por primera vez en unas elecciones autonómicas en la provincia de Barcelona, con un número de votos histórico: 948.202 en 1999, frente a los 620.756 conseguidos en 1995, dando de esta forma completamente la vuelta a los resultados obtenidos en 1995, cuando fue CiU la que obtuvo 953.419 votos.

Los socialistas logran de esta forma pasar del $25,4 \%$ del electorado, en las elecciones autonómicas de 1995 , al $40 \%$ de los sufragios en 1999, fortaleciendo de esta manera su presencia en esta provincia, al aumentar sus 22 diputados de las elecciones de 1995 hasta los 36 obtenidos en 1999, ganando la importante cantidad de 14 diputados.

El crecimiento espectacular de los socialistas de 19 puntos porcentuales ha sido posible gracias a la participación de una parte importante del electorado socialista que hasta ahora se abstenía sistemáticamente en las elecciones al Parlament, que ha sido ligeramente superior en la ciudad de Barcelona y la comarca del Barcelonès a la media catalana, pero que ha estado algo por debajo del resto del área metropolitana, siendo menor que la registrada hace cuatro años. 


\section{CUADRO 9}

Circunscripción de Barcelona

$\mathrm{N} .^{\circ}$ de electores: $4.037 .489-\mathrm{N} .^{\circ}$ de votantes: 2.376 .050

N. de votos en blanco: $21.926-\mathrm{N}^{\circ}$ de votos nulos: 5.175

\begin{tabular}{|c|c|c|c|c|}
\hline Partidos & $\begin{array}{c}\text { Votos } \\
1999\end{array}$ & $\begin{array}{c}\text { Votos } \\
1995\end{array}$ & $\begin{array}{c}\text { Diputados } \\
1999\end{array}$ & $\begin{array}{l}\text { Diputados } \\
\text { d1995 }\end{array}$ \\
\hline PSC-CPC .................. & 948.202 & 620.756 & 36 & 22 \\
\hline 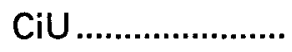 & 833.168 & 953.419 & 31 & 34 \\
\hline 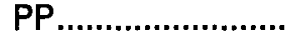 & 234.957 & 332.417 & 8 & 12 \\
\hline ERC & 183.270 & 212.335 & 7 & 7 \\
\hline IC-V ....................... & 78.441 & 274.222 & 3 & 10 \\
\hline EUiA ........................ & 38.836 & - & 0 & - \\
\hline
\end{tabular}

Fuente: Elaboración de cuadros números $9,10,11$ y 12 sobre datos oficiales facilitados por la Generalitat de Cataluña y publicados en el Diari Oficial núm. 3007, de 3 de diciembre de 1999. Otros datos en La Vanguardia, de 18 de octubre de 1999

ERC resiste el avance socialista y mantiene sus 7 diputados en Barcelona, a pesar de perder unos 30.000 votos. Peor parado sale el PP que pierde cuatro diputados y casi 100.000 votos con respecto a las autonómicas de 1995. Esta cifra de pérdida de votos es duplicada por IC$V$, que ha tenido que sufrir la competencia de EUiA, y por la pérdida del llamado "voto útil» en beneficio de sus aliados socialistas, con los que no se presentaba en coalición en esta circunscripción. IC-V ha tenido que ver cómo, de sus 10 diputados en 1995, no podía retener más que a duras penas 3 diputados en 1999.

En cuanto a la circunscripción de Tarragona, tal y como se puede ver en el cuadro 10, CiU consiguió retener la mayoría en votos, si bien ha perdido un diputado en relación a las anteriores elecciones autonómicas de 1995.

El escaño perdido por CiU en la circunscripción de Tarragona pasa a la coalición PSC-CPC-IC-V, que cuenta en el nuevo Parlament con 6 diputados, uno más de los que sumaban la unión de IC-V (1 diputado) y el PSC (4 diputados) en la anterior legislatura.

Lo más destacado de la configuración de las fuerzas políticas -ver cuadro 10- en la provincia de Tarragona es la firmeza del voto de PP y ERC, que con pocas diferencias en votos repiten resultado en escaños, aguantando bien la tendencia hacia la bipolarización y el "voto útil", que ha beneficiado a CiU y a los socialistas en otras circunscripciones. 
CUADRO 10

Circunscripción de Tarragona

$\mathrm{N} .{ }^{\circ}$ de electores: $487.363-\mathrm{N} .^{\circ}$ de votantes: 284.221

$\mathrm{N} .^{\circ}$ de votos en blanco: $2.652-\mathrm{N}^{\circ}$ de votos nulos: 961

\begin{tabular}{|c|c|c|c|c|}
\hline Partidos & $\begin{array}{c}\text { Votos } \\
1999\end{array}$ & $\begin{array}{c}\text { Votos } \\
1995\end{array}$ & $\begin{array}{l}\text { Diputa- } \\
\text { dos } 1999\end{array}$ & $\begin{array}{l}\text { Diputa- } \\
\text { dos } 1995\end{array}$ \\
\hline 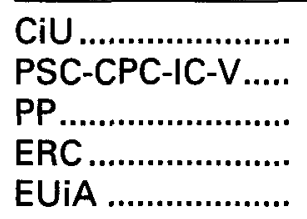 & $\begin{array}{c}116.974 \\
96.632 \\
30.108 \\
29.733 \\
2.198\end{array}$ & $\begin{array}{c}127.645 \\
68.576-19.042 \\
42.398 \\
32.661 \\
-\end{array}$ & $\begin{array}{r}8 \\
64 \\
2 \\
2 \\
0\end{array}$ & $\begin{array}{l}9 \\
\overline{2} \\
2 \\
-\end{array}$ \\
\hline
\end{tabular}

Fuente: Ibidem cuadro n.' 9.

En cuanto a la circunscripción de Girona, se mantiene el mismo equilibrio de fuerzas en escaños alcanzado tras los comicios autonómicos de 1995. CiU es la fuerza mayoritaria en Girona con un porcentaje de votos y número de escaños prácticamente inalterados, en relación con los últimos comicios autonómicos -ver cuadro 11-. Por otro lado, a pesar del avance de la coalición de Pasqual Maragall en otras circunscripciones, en Girona dicho avance no se ha producido y el porcentaje de votos de esa coalición ha sido prácticamente el mismo que hace cuatro años, -si se suman los porcentajes que entonces obtuvieron el PSC e IC-EV, que en 1995 se presentaron por separado-. ERC prácticamente repite tanto en número de votos como en escaños, mientras que PP, a pesar de la disminución en el número de votos-que lo sitúa casi dos puntos del porcentaje por debajo de los últimos comicios autonómicos-, consolida el diputado que consiguió en 1995.

\section{CUADRO 11}

Circunscripción de Girona

N. ${ }^{\circ}$ de electores: $455.778-N{ }^{\circ}$ de votantes: 283.346

$\mathrm{N} .{ }^{\circ}$ de votos en blanco: 2.426 - N. de votos nulos: 1.005

\begin{tabular}{|c|c|c|c|c|}
\hline Partidos & $\begin{array}{l}\text { Votos } \\
1999\end{array}$ & $\begin{array}{l}\text { Votos } \\
1995\end{array}$ & $\begin{array}{c}\text { Diputados } \\
1999\end{array}$ & $\begin{array}{c}\text { Diputados } \\
1995\end{array}$ \\
\hline CiU ............................ & 137.079 & 140.012 & 9 & 9 \\
\hline PSC-CPC-IC-V..... & 82.502 & $74.124-11.546$ & 5 & $5-0$ \\
\hline ERC $\ldots \ldots \ldots \ldots \ldots$ & 36.159 & 35.338 & 2 & 2 \\
\hline PP......................... & 17.079 & 22.618 & 1 & 1 \\
\hline EUiA ....................... & 2.493 & - & 0 & - \\
\hline
\end{tabular}

Fuente: Ibidem cuadro n: 9. 
Por último, en la circunscripción de Lleida, CiU conserva los 8 diputados obtenidos en los comicios de 1995, si bien no por la mayoría aplastante de entonces [ver cuadro 12], debido al significativo aumento de la coalición de Maragall, que consiguió en total cinco escaños -dos más de los que logró en las pasadas elecciones autonómicas- e incrementar en más de cinco puntos el porcentaje logrado por los socialistas e IC por separado -forma en la que concurrieron en 1995-. EI ascenso de la Coalició pel Canvi reviste un especial significado en Lleida, pues en esta circunscripción es donde por primera vez los socialistas superan a los nacionalistas en unas elecciones autonómicas.

Por otro lado, ERC y PP, al contrario de lo que había sucedido en la circunscripción de Tarragona, no han podido resistir en Lleida la fuerte bipolarización de la campaña electoral, experimentando una pérdida de votos -más pronunciada en el PP-, que lleva a que ambos partidos pierdan un escaño respectivamente en relación a las últimas elecciones autonómicas.

\section{CUADRO 12}

Circunscripción de Lleida

N. de electores: $312.961-\mathrm{N} .^{\circ}$ de votantes: 190.309

N. ${ }^{\circ}$ de votos en blanco: 1.964 - N. de votos nulos: 695

\begin{tabular}{|c|c|c|c|c|}
\hline Partidos & $\begin{array}{l}\text { Votos } \\
1999\end{array}$ & $\begin{array}{l}\text { Votos } \\
1995\end{array}$ & $\begin{array}{l}\text { Diputados } \\
1999\end{array}$ & $\begin{array}{c}\text { Diputados } \\
1995\end{array}$ \\
\hline $\mathrm{CiU}$ & 91.199 & 98.995 & 8 & 8 \\
\hline PSC-CPC-IC-V..... & 55.963 & $38.796-8.282$ & 5 & $3-0$ \\
\hline ERC $\ldots \ldots \ldots \ldots \ldots \ldots \ldots$ & 22.011 & 25.533 & 1 & 2 \\
\hline PP................................ & 15.121 & 24.319 & 1 & 2 \\
\hline EUiA ..................... & 927 & - & 0 & - \\
\hline
\end{tabular}

Fuente: Ibidem cuadro n. 9.

\section{PACTOS POST-ELECTORALES}

Tras las elecciones al Parlamento en Cataluña, la coalición gobernante CiU queda, como ya hemos visto, en una precaria situación a falta de los votos de otros partidos para conseguir la reelección de Jordi Pujol al frente del ejecutivo autonómico.

EI PSC seguirá insistiendo durante algunos días en su superioridad en las urnas -en cuanto al número de sufragios conseguidos-, 
hasta que, aceptando la contundencia de los resultados en escaños, se constituya en el principal partido de la oposición. El alza en votos del partido de Maragall viene acompañada del fracaso de IC-V y de EUiA, en medio de los reproches entre los partidarios de Anguita y los de Rafael Ribó, que reflejan el fracaso electoral de esa parte de la izquierda catalana.

Esquerra Unida i Alternativa (EUiA), la lista apadrinada por Julio Anguita, no sólo no obtuvo ningún escaño en las elecciones catalanas, sino que, según algún comentarista político, privó a Iniciativa per Catalunya-Vers -la coalición encabezada por Rafael Ribó de la que se ha escindido- de su cuarto diputado por Barcelona, puesto que, supuestamente, de no haberse "perdido" esos votos, la suma PSC-IC podría haber igualado los escaños alcanzados por CiU en el Parlament ${ }^{35}$.

Por su parte, ERC apuesta por exigir un alto precio político por su posible apoyo a CiU en su oferta de pacto post-electoral. Se propone por esta formación un pacto tripartito entre CiU, PSC y ERC, apartando incluso, si fuera necesario, a Pujol de la Presidencia de la Generalitat. Esta propuesta de Carod Rovira no tenía en realidad ningún futuro, pero revelaba claramente que ERC prefería renunciar a un poder escaso en la actualidad, para mostrarse en un futuro más reivindicativo frente a CiU a lo largo de la legislatura, en caso de que CiU prefiriese pactar con el PP.

El PP, a pesar del resultado electoral modesto -de sus 12 diputados-, puede representar a lo largo de la legislatura una fuerza política imprescindible para "moderar» la acción de gobierno de CiU en Cataluña -lo cual era uno de sus objetivos electorales-, a la vez que declara también su deseo de servir de "contrapeso a las pretensiones" de CiU en Madrid.

Después de mantener consultas con distintos grupos políticos, CiU se decantó por el acuerdo con el PP, merced al cual fue posible la elección -el viernes 5 de noviembre de 1999- del nuevo presidente del Parlament de Catalunya, Joan Rigol -que obtuvo 68 votos provenientes de los 56 diputados de CiU y los 12 del PP-. La elección estuvo muy reñida y se ganó por un solo voto de diferencia sobre el candidato del PSC-CPC, que obtuvo 67 votos provenientes de sus 50 diputados, de los 12 de ERC y los 5 de IC- $V$, dividiéndose la Cámara en dos bloques, al verse forzada Esquerra a votar al candidato del PSC para no quedarse fuera de la Mesa del Parlament ${ }^{36}$. 
La diferencia tan ajustada entre los candidatos a la presidencia del Parlament, en la que la mayoría puede depender de un solo voto, motivará un debate interno en la Cámara, en la que van a estar de acuerdo la mayoría de los partidos catalanes en proponer que en el futuro sea incompatible el cargo de diputado en el Parlament con el de senador autonómico, lo cual requeriría cambiar el Estatut para modificar el actual sistema de elección de los siete representantes de Cataluña en la Cámara alta. En la actualidad, el sistema fijado en el artículo 34 del Estatut obliga a que los senadores sean a la vez diputados del Parlament ${ }^{37}$.

No obstante, el acuerdo de última hora suscrito entre CiU v el PP en los pasillos del Parlament, el día de la elección de Jordi Pujol como presidente de la Generalitat -martes 16 de noviembre de 1999-, cierra por ahora la puerta a cualquier reforma del Estatut y de la Constitución. El texto acordado de 17 puntos deja claro en su preámbulo que Cataluña se compromete a desarrollar su autogobierno dentro del marco constitucional y estatutario vigente, a respetar la pluralidad social y lingüística de $\mathrm{Ca}$ taluña y a rechazar fórmulas de financiación "no previstas en el Estatut», en una clara referencia al concierto económico que pide Esquerra ${ }^{38}$.

Desde CiU se ha tratado de restar transcendencia al pacto suscrito con el PP, declarando que este documento no hace más que reiterar los compromisos exhibidos por la coalición durante la campaña electoral. Desde el PP se ha recordado también, por su parte, que estos eran los temas primordiales del discurso del PP durante la campaña ${ }^{39}$.

En cualquier caso, a pesar de las declaraciones efectuadas por los dos partidos, sorprendió que, contra todo pronóstico, Jordi Pujol consiguiera por primera vez en minoría, ser investido president en la primera vuelta -por mayoría absoluta-, sin necesidad de una segunda votación, merced a los votos positivos de su partido y del PP, que suponen un total de votos a su favor de 68 , frente a los 55 votos en con-

37 Los republicanos plantean esta cuestión como una simple modificación "técnica" del Estatut, que permitiría a la Cámara catalana seguir su propio ritmo de trabajo, en lugar de organizar su calendario de plenos en función de las sesiones del Senado para que sea posible la compatibilidad de los escaños. Se propone por Esquerra aplicar el sistema del Parlamento vasco, realizando los cambios oportunos tanto en el Estatut como en el reglamento del Parlament. El Periódico de Catalunya (30-11-1999).

38 El Periódico de Catalunya (17-11-1999).

39 No obstante, a pesar de estas declaraciones de buena voluntad, el acuerdo fue realizado por escrito, dado que el presidente del PP en Cataluña, Alberto FERNÁNDEZ, habia declarado al entrar en la Cámara, en el momento de votar, que "algunas cosas que se dicen deben quedar en un papel». El Mundo (17-11-1999). 
tra del PSC-CC y IC-V; logrando que los 12 diputados de ERC -fuerza política que había suscrito también un acuerdo con CiU de 12 puntos-se abstuviesen en la votación de investidura.

\section{ANÁLISIS DE LOS RESULTADOS ELECTORALES}

Como es bien conocido, la orientación del voto en nuestro país encuentra modelos territoriales diversos, en los que la dimensión de la identidad nacional e ideológica de los conflictos (cleavages) explican el éxito electoral de las formaciones nacionalistas/regionalistas, que en ciertos $\operatorname{casos}^{40}$ difiere claramente del modelo antagónico de los partidos de ámbito mayoritario a nivel estatal.

Por eso, en el caso que nos ocupa, a la hora de analizar los resultados electorales en el ámbito autonómico, debemos tener muy presente la influencia decisiva de las reivindicaciones sociales e históricas específicas ${ }^{41}$, que ayudan a explicar en algunos casos la configuración de las fuerzas políticas a nivel autonómico. De ahí se pueden inferir algunas diferencias, cuando, no obstante, la normativa electoral no es sustancialmente diferente ${ }^{42}$, pues en estos casos las Comunidades Autónomas, aun teniendo libertad para su configuración dentro del respeto a los límites constitucionales y estatutarios, han reiterado el conjunto de elementos fijados en el sistema electoral general ${ }^{43}$.

No obstante, el criterio de identidad nacional no sería el único factor a tener en cuenta ${ }^{44}$, por lo que también habría que considerar in-

40 El modelo de Comunidades Autónomas que reproducen este esquema son Cataluña, Navarra, País Vasco y, en menor grado Galicia. Éstas serían consideradas las Comunidades Autónomas más relevantes a la hora de considerar modelos territoriales diversos, aunque evidentemente hay otras Comunidades que cuentan con partidos nacionalistas $y$ regionalistas representados en sus correspondientes Parlamentos autonómicos.

41 LiNz, J; MONTERO, J. R. Crisis y cambio: electores y partidos en la España de los años ochenta. Madrid, C.E.P.C. págs. 525-586.

42 Ver pie de página número 23.

43 Santolaya Machetti, P. Manual de Procedimiento electoral. Secretaría General Técnica del Ministerio del Interior, Madrid, 1999. pág. 37.

44 Si hay que hacer caso a lo que dicen las encuestas, la publicada por $\mathrm{La}$ Vanguardia nos informa, que del electorado en Cataluña, el $21 \%$ de los catalanes se declara independentista, un $61 \%$ en contra y un $18 \%$ al margen. Según el último sondeo del CIS, el $45 \%$ de los catalanes se considera tan español como catalán, un $23 \%$ más catalán que español, un $9 \%$ sólo se siente español y un $14 \%$ sólo catalán. Vid. $A B C(15-10-1999)$. 
fluyentes en los resultados electorales otras bases de diversidad política, ideológica, cultural, socioeconómica o incluso geográfica, que se encuentran presentes en el Estado autonómico. La valoración por parte de los ciudadanos de los logros conseguidos en este ámbito será, por tanto, un valioso elemento de comprensión de la reacción popular ante los comicios. Por ejemplo, a la hora de enjuiciar los logros alcanzados en promoción económica exterior -que en Cataluña es valorada por los agentes socioeconómicos de forma muy positiva-, así como el éxito en la política territorial, $u$ otras esferas también muy importantes como obras públicas, política educativa, etc ${ }^{45}$.

No obstante, descendiendo al caso estudiado, hemos de tener presente que el éxito electoral del nacionalismo moderado de Jordi Pujol, es decir, la mayoría alcanzada por CiU en estas elecciones de 1999 -del $37,7 \%$ de los votos- representa una "mayoría minoritaria", que necesita del apoyo de otros grupos políticos para sacar adelante los proyectos legislativos de más envergadura.

Por otro lado, hay que tener en cuenta que en Cataluña, de las siete elecciones a Cortes Generales (de 1977 a 1996) y de las seis elecciones celebradas para el Parlamento de Cataluña (de 1980 a 1999), la abstención siempre castigase más a los comicios catalanes, en lo que hasta ahora se ha venido considerando como desinterés de ese sector abstencionista, que se supone "no nacionalista", hacia las elecciones autonómicas.

Además, recordemos que anteriormente nos hemos referido a un fenómeno electoral muy curioso, al que denominamos voto dual, que sin duda viene a complicar más aún el panorama catalán. Hablábamos del voto dual para referirnos al hecho de que un segmento de los ciudadanos catalanes cambian regularmente el sentido de su sufragio, según el ámbito de cada convocatoria, respaldando a los socialistas en las elecciones generales y a $\mathrm{CiU}$ en las autonómicas.

No obstante, con toda la prudencia que aconseja un marco tan rico y complejo como el catalán, creemos que no se debe contraponer estos dos tipos de elecciones, pues aun cuando tengan distinta naturaleza, la práctica política ha puesto de relieve que las elecciones gene-

45 Precisamente en el sistema político catalán encontramos un alto grado de intermediación de esos factores con el sistema autonómico y estatal y los grupos de intereses en general. Vid. Morata, F. «Institucionalización y rendimiento político del Estado Autonómico (Un estudio comparado: Andalucía, Cataluña, Galicia y Comunidad Valenciana)", en Revista de Estudios Políticos. Núm. 76. Abril-Junio 1992. pág. 276. 
rales y las autonómicas no representan compartimentos electorales estancos, pues $\mathrm{CiU}$ ha contribuido muy positivamente a la buena marcha económica y a la gobernabilidad de España, a la vez que desde 1993, gracias a su participación en la política general del Estado, ha incrementado también notablemente su nivel de autogobierno ${ }^{46}$, a la vez que, después del resultado electoral del 17 de octubre, se abre la vía de colaboración en el marco autonómico entre un partido de ámbito estatal y CiU, para que Jordi Pujol pueda desbloquear, si hace falta, la gobernabilidad de la Generalitat.

Centrándonos más propiamente en las principales consecuencias de las elecciones autonómicas del 17 de octubre, vamos a tratar de sintetizar las cuestiones más relevantes que se han producido como resultado de dichos comicios, según lo que hemos ido viendo a lo largo de este trabajo.

En primer lugar, hay que resaltar la incuestionable sexta victoria consecutiva de Jordi Pujol -al haber conseguido más apoyos politicos en el Parlament-, lo que supone un hecho extraordinario en un sistema democrático, que ha sido seguido con curiosidad por la prensa extranjera, que ha comparado a Pujol con distintos líderes políticos que han dilatado durante mucho tiempo su presencia en la política activa. En Alemania, este fenómeno ha tenido quizá un mayor seguimiento, posiblemente porque la estructura descentralizada de ambos países supone intereses mutuos, llegándose a comparar a Jordi Pujol con Franz Josef Strauss, que ejerció el poder durante largo tiempo en Baviera ${ }^{47}$.

Efectivamente, Jordi Pujol es el indiscutible árbitro de la situación catalana tras las elecciones del 17 de octubre, ya que el artículo 36 del Estatuto de Cataluña no deja lugar a dudas, al establecer, en relación al presidente de la Generalitat, que éste "será elegido entre sus miembros por el Parlamenton. Es decir, se trata de elecciones al Parlament y gana quien consigue más apoyo parlamentario. Por eso, si bien el vencedor en votos tiene que ser tomado en consideración en las consultas para formar gobierno, el mayor número de votos no garantiza -como tampoco lo hace que un partido tenga más escaños que otroderecho alguno al gobierno, pues las alianzas postelectorales pueden

${ }^{46}$ Por ejemplo el traspaso de las políticas activas del INEM, la gestión de! tráfico a los Mossos d’Esquadra, etc.

47 Los comicios catalanes han ocupado la primera plana de diarios como el "Berliner Zeitung" o lugares destacados en la información del "Frankfurter Allegemeine Zeitung", el "Süddeutsche Zeitung", etc. 
propiciar una mayoría en la Cámara suficiente para formar gobierno. Es decir, estamos ante la versión más pura del parlamentarismo monista, en la que el que gobierna lo hace al conseguir ser elegido y contar con la confianza de la mayoría de la Cámara ${ }^{48}$.

La legitimidad del gobierno de CiU no puede, por tanto, ponerse en entredicho, dado que en el régimen parlamentario la legitimidad del gobierno surge de la voluntad del Parlamento. El hecho de que la mayoría parlamentaria pueda no corresponderse con la voluntad de los electores expresada en las urnas es, a juicio de Jaume Colomer ${ }^{49}$, un problema de naturaleza política, que podría plantearse mediante una posible reforma del sistema electoral que corrija, entre otras, la decisión política de si se debe primar con algunos escaños más de los que en principio les correspondería a las circunscripciones menos pobladas, para protegerlas del excesivo hegemonismo de las circunscripciones más pobladas. En cualquier caso, la legitimidad del gobierno es incuestionable, pues, como ya hemos dicho, en el régimen parlamentario los gobiernos están sustentados en las mayorias parlamentarias, ya sean resultado de una o de varias fuerzas políticas.

La segunda valoración de nuestro análisis, según los resultados de los comicios del 17 de octubre, muestra un interesantísimo debate político y académico en torno a cómo es posible ganar en votos pero perder en escaños. Si en la anterior consideración analizábamos las consecuencias de los resultados sobre la gobernabilidad, en este caso tendremos que centrar nuestra atención sobre la representatividad del sistema electoral ${ }^{50}$, basado en la fórmula de escrutinio de la media más alta o más conocida como la fórmula D'Hondt, que como ya resulta bien sabido penaliza a los partidos minoritarios a la hora de repartir escaños no aprovechando los restos y que a la vez en las circunscripciones de pequeño tamaño tiene un efecto muy poco proporcional. Efectivamente, Arend Lijphart, en su estudio comparativo de veinticinco regímenes democráticos, resalta que, en el caso de España, el sistema electoral proporcional tiene curiosamente un alto grado de no proporcionalidad ya que en nuestro país la representación proporcional "se aplica a distritos de reducida magnitud (...) y no

48 Herrero de Miñón, M. «Mecánica o dialéctica» en La Vanguardia (24-101999). Ver también, Santamaría, J. "las reglas del juego», en El País (29-10-1999).

49 Colomer, J. «Legitimidad y sistema electoral» en El Periódico de Catalunya (20-10-1999).

${ }^{50}$ Carrillo, M. "Sistema parlamentario y elecciones", en El Periódico de Catalunya (25-10-1999). 
se recurre al procedimiento de los escaños suplementarios, a escala autonómica o estatal, para hacer más proporcional la distribución global de escaños»"51.

Además, la dimensión demográfica de las circunscripciones electorales van a determinar -como ya hemos visto anteriormente-que la obtención de escaños sea más costosa en votos en las circunscripciones más pobladas. De esta forma, en Barcelona la disposición transitoria cuarta, apartado segundo, del Estatut de Catalunya, otorga un Diputado por cada 50.000 habitantes con un máximo de 86 Diputados, mientras que en las circunscripciones de Girona, Lleida y Tarragona se rebaja el requisito a $\mathbf{4 0 . 0 0 0}$ habitantes por Diputado, estableciéndose respectivamente 17,15 y 18 Diputados, y se fija para estas últimas un mínimo de seis Diputados ${ }^{52}$.

Para Carles Castro, esta distribución dificulta la posibilidad de que se reparta el voto de una forma más homogénea, pues, a pesar de algunas declaraciones sobre convertir a Cataluña en una circunscripción única, en realidad se ha preferido no tocar las cuatro provincias heredadas como circunscripciones electorales. El hecho de que el propio Estatut establezca este "plus» de seis escaños mínimos para Tarragona, Lleida y Girona, al margen de la cifra de su peso demográfico, es considerado por este autor como claramente distorsionante ${ }^{53}$.

Por otro lado, Carles Castro también ha resaltado una distorsión similar a la catalana -en cuanto a la relación entre votos y escaños- en las elecciones a las Cortes de Aragón de 1991, pues sumando los votos y escaños conseguidos en dichas elecciones de la izquierda (PSOE e IU), habían obtenido 33 escaños con un $46,74 \%$ de los votos, mientras la centroderecha (PP y PAR) obtuvo 34 escaños con un $45 \%$ de los votos ${ }^{54}$. Lógicamente este caso no es exactamente

51 LIJPHART, A. Las democracias contemporáneas. Barcelona, 1991. pág. 234.

52 Ley Orgánica 4/1979, de 18 de diciembre, del Estatuto de Autonomía de Cataluña.

53 Para este autor el último escaño puede costar en la circunscripción de Barcelona 30.000 papeletas, mientras en Lleida es posible obtenerlo por 11.000 y en Tarragona por 14.000. Vid. Castro, C. "Votos rigurosamente desiguales", en La Vanguardia (20-10-1999).

54 Los resultados, publicados en el Boletín Oficial de Aragón (BOA n.' 80, de 1 de julio de 1991), reflejan un número de votos para el PSOE de 247.485, con 30 escaños; para el PAR, 151.420, con 17 escaños; el PP, 126.892, con 17 escaños e IU, 41.367, con 3 escaños. Vid. BOA n. 80 , de 1 de julio de 1991. Los datos se encuentran también recogidos en el artículo de Fernández-Miranda, C. "Análisis de las elecciones autonómicas y municipales de 26 de mayo de 1991, en Revista de Derecho Político, n. 35. UNED. 1992. pág. 246. 
igual al de las elecciones catalanas de 1999, en el que las dos grandes coaliciones extraen unos resultados muy parejos directamente de las urnas y no como resultado de pactos post-electorales, si bien, no obstante, resulta especialmente interesante el supuesto aragonés, ya que se puede asimilar en el hecho, no sólo de la poca proporcionalidad que en ciertas circunscripciones demuestra nuestro sistema electoral, sino también en cuanto que el resultado final se encuentre en función de los compromisos políticos, que, como hemos visto en un sistema parlamentario, pueden dar el gobierno a un partido distinto del más votado si cuenta con los oportunos apoyos parlamentarios ${ }^{55}$.

A pesar de los posibles precedentes, en la historia de nuestra democracia nunca hasta ahora se había apreciado, en nuestra opinión, con tanta claridad las distorsiones que la "geografía electoral" puede producir sobre el resultado final. La controversia política derivada de este hecho se reveló en la misma noche de las elecciones catalanas, cuando un líder histórico socialista calificó la representación política como el "triunfo de las hectáreas sobre las personas" ${ }^{56}$, mientras que otro militante de CiU señalaba que no seria justo "que se negase ese contrapeso a las comarcas ${ }^{57}$.

Francesc Pallarès traza la clave de las elecciones según el distinto comportamiento electoral de los catalanes en función de la geografía electoral. Según este autor, Maragall se ha caracterizado por un discurso urbano, ha dado una imagen muy ligada a la Barcelona olímpica, a su gestión urbana y a la defensa metropolitana, lo cual explica los buenos resultados para los socialistas en Barcelona. No obstante, CiU está más extendida por el territorio catalán, lo que le permite una mejor implantación y organización. De Iniciativa per Catalunya IC, este autor cree que no tiene una fuerte base en la Cataluña interior ${ }^{58}$.

Para Gabriel Colomé, el hecho de que los socialistas capten un electorado más urbano, mientras que CiU logra vencer en las zonas ru-

55 Otro caso que puede ilustrar también el desfase entre votos y escaños son las elecciones autonómicas de 1986 en el País Vasco, en las que el PNV ganó las elecciones sumando 271.000 votos, con 17 escaños, mientras que el PSOE con 19.000 votos menos obtuvo 19. No obstante, este supuesto tampoco sería exactamente igual que las elecciones catalanas, ya que en el País Vasco cada provincia cuenta con los mismos escaños al margen del censo electoral. Según el artículo 10 de la Ley 5/1990, de 15 de junio, de elecciones al Parlamento Vasco, se eligen veinte parlamentarios por cada circunscripción.

56 La Vanguardia (24-10-1999).

57 lbidem.

58 Pallarés, F. "Las claves de las elecciones", en La Vanguardia (24-10-1999). 
rales, no es más que una demostración de que "las estructuras de cada partido tipifican en gran medida las estructuras de sus electorados ${ }^{59}$. Por otro lado, este autor ve el mapa político surgido de las elecciones del 17 de octubre, en cuanto a cómo ha quedado el espacio electoral, de la siguiente forma: la fragmentación del espacio IC-V, EUiA y Els Verds ha impedido que IC-V pudiese obtener unos resultados que evitasen el traspaso de votos hacia la coalición de Maragall. La bipolarización en bloques entre socialistas y $\mathrm{CiU}$, ha permitido, sin embargo, que ERC pudiese mantener su espacio electoral, mientras que el PP ha conseguido frenar en gran medida la pérdida de votos.

Por último, la tercera valoración de las elecciones, en nuestro análisis, es la concerniente a la abstención. La participación en las elecciones autonómicas catalanas se ha situado en torno a un $60 \%$ de media [ver cuadro número 4]. Esta participación ha parecido baja, ya que el resultado a priori de las elecciones se mostraba en algunas encuestas incierto, dado que los principales rivales mostraban posiciones muy niveladas, como ha sido posible comprobar en los resultados electorales, razón por la que se esperaba una mayor participación. No obstante, otros sondeos revelaban que una gran mayoría de los ciudadanos daba por hecha la victoria de Pujol, lo que ha podido desmotivar no sólo al propio electorado de CiU, sino al del resto de las fuerzas políticas que concurrían a las elecciones.

Para Ernest Lluch el problema de la abstención es preocupante, ya que muestra "que la integración política de los ciudadanos de Cataluña no solamente es baja, sino que disminuye "60. Para este autor, aunque la abstención sea mayor entre los electores que no nacieron en $\mathrm{Ca}$ taluña o entre sus descendientes directos, no por eso es posible generalizar el fenómeno, puesto que donde la participación ha bajado más -por ejemplo en la provincia de Girona- los catalanes de origen son clara mayoría.

La baja participación es también preocupante para Carles Castro, pues sólo Baleares ha registrado una participación inferior a Cataluña, mientras que en el resto de las autonomías se ha observado una participación hasta 18 puntos superior ${ }^{61}$.

59 Colomé, G. "Elecciones de geometría variable«, en El Periódico de Catalunya (19-10-1999).

60 La Vanguardia (21-10-1999).

61 CAStro, C. "Los ricos también votan", en La Vanguardia (24-10-1999). Ver también del mismo autor: "En estado de sitio“, en La Vanguardia (15-11-1999). 
Para este autor, un estudio detallado de las cifras de participación parece atribuir una imagen de las elecciones catalanas protagonizada esencialmente por las clases medias autóctonas, en la que en los grandes asentamientos urbanos de la periferia barcelonesa, con una gran mayoría de población obrera e inmigrante, la participación apenas supera el $50 \%$, mientras que en otras zonas como Vic, Manresa o Igualada, la participación puede sobrepasar el $60 \%$ e incluso en algún caso el $65 \%{ }^{62}$.

Según Francesc Pallarés, el descenso de la participación ha sido general en todas las comarcas, si bien esta disminución no ha sido homogénea. En su opinión, una posible explicación para este clima de mayor o menor movilización electoral «encuentra su referencia en la evolución del proceso político en el poder central del Estado" ${ }^{63}$.

Esperemos que en el futuro la participación sea más alta y motive un mayor interés en el electorado la cita del año 2004, en la que -como ya hemos dicho anteriormente-se debe culminar el traspaso de competencias desde la Administración Central a las distintas Comunidades Autónomas.

62 Según Carles CAStro, la abstención en zonas acomodadas como SarriàSant Gervasi o el Eixample, no supera el $35 \%$, mientras en barrios populares se puede situar entre el 35 y el $40 \%$, sobrepasando claramente el $40 \%$ en los que cuentan con una numerosa población trabajadora o inmigrante, como en Ciutat Vella, en la que la abstención ronda el $50 \%$, oscilando la diferencia entre barrios pobres y ricos entre los 9 y los 18 puntos, razón por la que el articulista rotula su trabajo periodístico con el título: "los ricos también votan".

63 Pallarès, F. "¿Qué ha pasado con la participación?", en El Periódico de Catalunya (20-10-1999). 